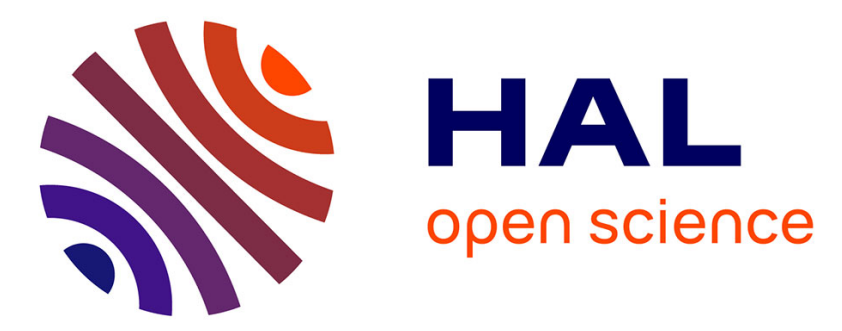

\title{
DESORPTION YIELDS USING keV POLYATOMIC PROJECTILES
}

\author{
M. Blain, S. Della-Negra, H. Joret, Y. Le Beyec, E. Schweikert
}

\section{To cite this version:}

M. Blain, S. Della-Negra, H. Joret, Y. Le Beyec, E. Schweikert. DESORPTION YIELDS USING keV POLYATOMIC PROJECTILES. International Workshop on $\mathrm{MeV}$ and $\mathrm{KeV}$ Ions and Cluster Interactions with Surfaces and Materials 2, 1988, Orsay, France. pp.C2-147-C2-153, 10.1051/jphyscol:1989225 . jpa-00229423

\section{HAL Id: jpa-00229423 https://hal.science/jpa-00229423}

Submitted on 1 Jan 1989

HAL is a multi-disciplinary open access archive for the deposit and dissemination of scientific research documents, whether they are published or not. The documents may come from teaching and research institutions in France or abroad, or from public or private research centers.
L'archive ouverte pluridisciplinaire HAL, est destinée au dépôt et à la diffusion de documents scientifiques de niveau recherche, publiés ou non, émanant des établissements d'enseignement et de recherche français ou étrangers, des laboratoires publics ou privés. 
JOURNAL DE PHYSIQUE

Colloque C2, supplément au $n^{\circ} 2$, Tome 50, février 1989

DESORPTION YIELDS USING keV POLYATOMIC PROJECTILES

M.G. BLAIN, S. DELLA-NEGRA ${ }^{*}$, H. JORET ${ }^{*}$, Y. LE BEYEC ${ }^{*}$ and E.A. SCHWEIKERT

Texas $A$ and $M$ University, Department of Chemistry, College station, TX 77830-3144, U.S.A.

*Institut de Physique Nucléaire, B.P. $n^{\circ} 1, F-91406$ orsay Cedex, France

Résumé : Naus avons étudié l'émission d'ions négatifs a partir de cibles solides arganiques bombardées par des ions moleculaires et des agrégats atomiques. Nous présentons ici les resultats obtenus avec une cible de phenylalanine. Nous avons utilise les projectiles organiques de masse 73 $\left[S i\left(\mathrm{CH}_{3}\right)^{+}\right], 147\left[\mathrm{Si}\left(\mathrm{CH}_{3}\right)_{3} \mathrm{OSi}\left(\mathrm{CH}_{3}\right)_{2}^{+}{ }^{+}\right.$, 300 [ion moleculaire du coronène $\left[{ }_{24} \mathrm{H}_{12}^{+{ }^{3}}\right]$, 598 [1e dimère du coronène $\left.2(\mathrm{M}-\mathrm{H})\right]^{+}$, et les ions atoniques et polyatomiques de masse $133\left[\mathrm{CCS}^{+}, 393\left[\mathrm{Cs}_{2} \mathrm{I}^{+}, 653 \mathrm{CCs}_{3} \mathrm{I}^{+}\right.\right.$. Ces ions primaires ont eté produits en bombardant une cible de coronéne et de CsI par des produits de fission du ${ }^{252}$ Cf. Ensuite ces ions ont ete acceleres et facalises sur 1 'échantilion a etudier. Des mesures de temps de val saphistiquées des ions primaires et secondaires ont ete executés avec un systeme d'acquisition de données spéciales. Tous les temps de vol ant éte enregistres simul tanément.

Le rendement des ions moléculaires de phenylalanine a été étudié en fonction de l'energie et de la masse des projectiles. Une grande augmentation du rendement est observée aver 1 'énergie et la masse.

Abstract = We have studied the negative secondary ion emission fram solid organic targets bombarded by molecular ions and cluster ions. As an example we present here the results obtained with the compound phenylalanine- We have used organic projectiles of mass $73\left[5 i\left(\mathrm{CH}_{3}\right)\right]^{+}, 147\left[\mathrm{Si}\left(\mathrm{CH}_{3}\right)_{3} \mathrm{DSi}\left(\mathrm{CH}_{3}\right)\right]^{+}, 300$ [molecular ion of coronene $\left.\mathrm{C}_{24} \mathrm{H}_{12}\right]^{+}$, 598 [coronene dimer $2\left(\mathrm{M}-\mathrm{H}^{+}\right]^{+}$, and atomic and polyatanic ions of mass $\left.\left.133[\mathrm{Cs}]^{+}, 393 \mathrm{CCs}_{2} 1\right]^{+}, 653 \mathrm{CCs}_{3} \mathrm{I}_{2}\right]^{+}$. These primary ions have been produced in the bombardment of targets of coronene and CsI by fission fragment from a ${ }^{252} \mathrm{Cf}$ source. They were accelerated and focussed on the sample target. Sophisticated time of flight measurements of the primary and secondary ions have been performed with a special data acquisition systen. All the time of $f 1$ ight mass spectra were recorded at one.

The secondary molecular ion yield of the phenilalanine $(M-H)^{-}=164$ has been studied as a function of the energy of impact and of the mass of the projectile. A large enhancement of the yield with the mass and the energy is abserved. 


\section{INTRODUCTION}

Recently there has been much interest in the secondary ion emission from materials induced by cluster ion bombardment /1/. The incident cluster ions have velocities in three different regimes = greater than the Bohr velocity, $v_{0}=0.22 \mathrm{~cm} / n s e c$ ( $\left.f a s t\right)$, approximately equal to $v_{0}$, and much less than $v_{0}$ (slow). The reason for the interest in cluster induced ion emission is the increased secondary ion yields when compared with single atom inn projectile yields of the same charge state. In this paper, we describe the experimental procedure for obtaining quantitative yields of negative ions desorbed by slow (keV) incident positive eluster ions and we present some recent results for the yield of an organic compound phenylalanine desorbed by the molecular ian of coronene and by CsI cluster ions.

\section{EXPERTMENTAL}

The experiments were performed at the Institut de Physique Nucleaire in Orsay, France. The experimental approach for generating and accelerating variaus cluster ions for use as projectiles is described elsewhere $12 /$. Briefly, the cluster ions (as well as single atom ion species\} are produced by fission fragment induced desorption from the appropriate material deposited on a metallic surface (aluminized mylar). This surface is at a pasitive potential $U_{1}$. The desorbed ions (called primary ions in the following) are accelerated by an extraction grid at ground and travel in a field free region of $15 \mathrm{~cm}$. At the end of this region the primary ions bombard a sample surface titled by $20^{\circ}$ with respect to the primary beam direction ion. Under impact, electrons and negative ions are emitted from the surface lbiased at a negative potential $\left.\mathrm{U}_{2}\right)$, accelerated into a second field free region, and detected by a set af channel plates CCEMAZ in Fig. 1). The start signal is given by the complementary fission fragment in the detector CEMA1.

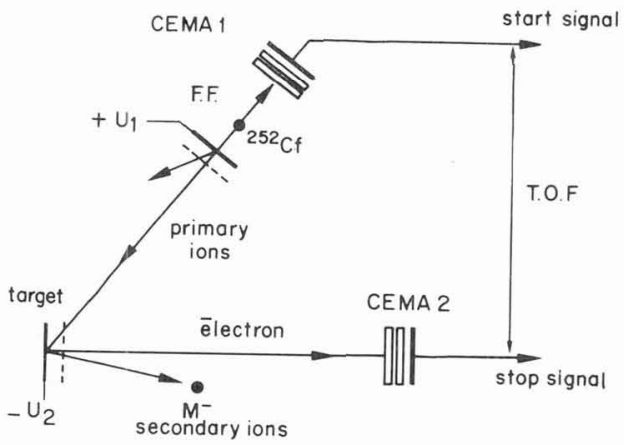

Fiqure 1 : Experimental set up.

The electrons are used as stop signals for the primary ion time of flight (TIF) measurements. In addition the stop signals generated by the secondary negative ions are also recorded. The spectrum shown in Fig. 2a, measured with the IPN multistop time-to-digital converted (TDC), is therefore the sum of two time of flight (TOF) spectra: 

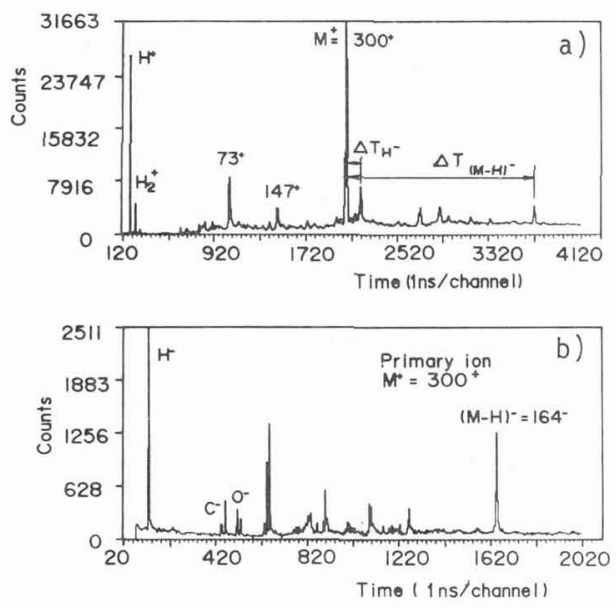

\section{Figure 2 :}

a) Total TOF spectrum : primary ians from a coronene target and secondary ions from a phenilalanine target isee text).

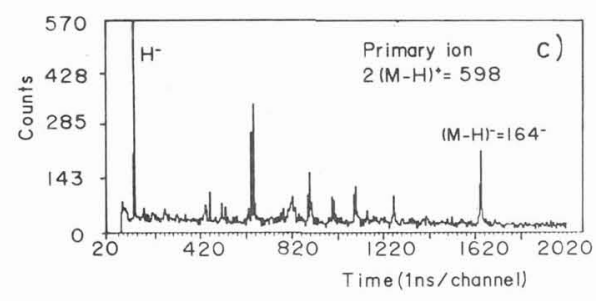

b) Secondary ion TOF spectrum generated by the impact of mass $M^{+}=300$ on the phenilalanine target. A coincidence time window has been set (on mass 300 in the spectrum $2 a$.

- the Tof spectrum of the primary ions (start with fission fragments from ${ }^{252}$ Cf and stops from electrons),

- the raf spectrum of the secondary ions (same start and stops from secandary ion impacts on CEMA2).

The first part of the Tof spectrum looks like a regular Tof spectrum of coronene desorbed by fission fragments with the presence of the peaks $\mathrm{H}^{+}, \mathrm{H}_{z}^{+}$, $H_{3}^{+} \ldots M^{+}=300$ and $2(M-H)^{+}=598$. However almost every peak can be considered as a time origin for the secondary ion time of flight spectrum. For example, the first peak after $M^{+}=300$ corresponds to the emissions of $H^{-}$ions due to the impact of $M^{+}=300$ on the phenylalanine sample. The time difference between $\mathrm{M}^{+}=300$ and another peak (see Fig. 2a) in the spectrum allows also to identify the presence of the molecular ians of phenylalanine $\left.\left(\mathrm{CM}_{-\mathrm{H}}\right]^{-}=164\right)$ desarbed by impact of $M^{+}=300$. Only a few mass assignments can be made in this way although the spectrum, which is very complex, contains much more information. Several secondary ion TOF peaks are masked by the background af the primary ion TOF.

To overcome these difficulties we have used a special data acquisition systeme described in ref/3/. A TOC event is composed of one start fallowed by many staps on a certain time range (B microsecands [13 bits] in the present experiment). Anywhere in this time range, it is possible to select a time window which can be used as a time origin for time measurements with the following stop signals. The result of the time digital conversion with the new origin is stored (event by event) in a special memory and gives rise to a specific Tof spectrum. Coincidence windows can be set to a width of about 10 

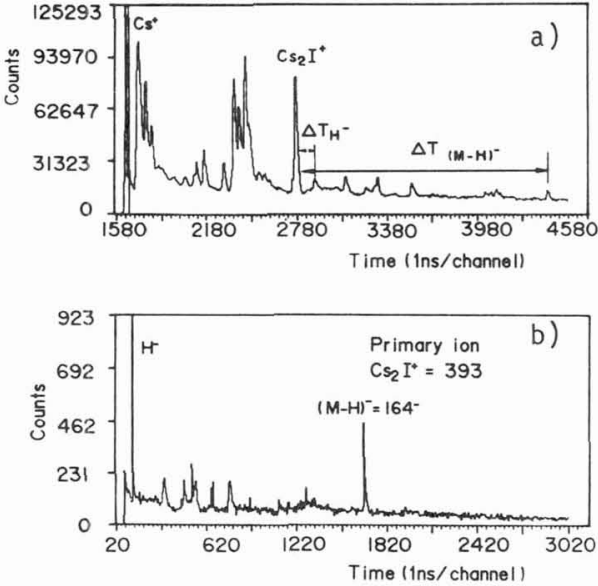

Eiqure $\underline{3}$ :

a) Total Tof spectrum = primary ions from a CsI target and secondary ions from a phenylalanine target.

b) Secandary ion TOF spectrum with a time origin corresppinding to the impart of $\mathrm{Cs}_{2} \mathrm{I}^{\mathrm{f}}$ on the sample.

channels on any peak of interest in the total Taf spectrum. By this coincidence counting method, individual spectra are extracted from the total Tof spectrum in real time during the data acquisition. As examples, Figures $2 b$ and $2 \mathrm{c}$ show spectra of ions desarbed from phenylalanine target due to the impact by the molecular ions of coronene $\left.\mathrm{M}^{+}=300\right)$ and due to the impact by the dimer $\left(2[\mathrm{M}-\mathrm{H}]^{+}=598\right)$. the two spectra are similar but the secondary ion yields (with respect to the number of primary ians bambarding the sample) are different.

A more complex example is shown in Fig. 3a and 3b. The phenylalanine target is bombarded by cesium ions and by cesium indide clusters (the coronene deposit has been replaced by a CsI deposit-see Fig. 1-1. Fig. 3a shows a total Tof spectrum. The peaks are due to the detection of electrons as stop signals as well as secondary ions generated by impacts of $\mathrm{Cs}^{+}, \mathrm{Cs}_{2} \mathrm{I}^{+}, \ldots$ and other primary ions on the phenylalanine sample. In Fig. 3b the time origin is the instant of impact of $\mathrm{Cs}_{2} \mathrm{I}^{+}$only and the corresponding time of flight spectrum of phenylalanine is observed. The molecular ion $(M-H)^{-}$of phenylalanine desarbed by $\mathrm{Cs}_{2} \mathrm{I}^{+}$is clearly seen.

This new method of time of flight measurement allows to extract several spectra from one single spectrum. The experimental conditions are kept the same during the experiment (same target, same detection...). the secondary ion yields due to the bombardment of the target by different kinds of projectiles can be extracted from one experiment.

The emission yield for an ian of mass $M$ is given by :

$$
Y_{M}=\left(N_{M}-N_{M}[B G]\right) /\left(N_{P I}-N_{P I}[B G]\right)
$$

$N_{M}$ is the number of counts in the peak of mass $M$ in the TuF spectrum in coincidence with the primary ions. 
$N_{M}[B G]$ is the number of counts in the peak of mass $M$ in the rof spectrum measured in coincidence with a time window set on the background clase to the primary ions.

$N_{P I}$ and $N_{P I}[B G]$ are the number of counts in the $t i m e$ windaw set on the peak and the backgroung. $N_{P I}-N_{p I}[B G]$ is the number of start events for a correlated spectrum. It is assumed in relation (1) that we have single impact on the sample. This is not the case when $\mathrm{Cs}^{+}$ions are emitted from the CsI depasit by the fission fragments and therefore a correction must be made on the number $N_{P I}$ to obtain the true number of primary ions of Cs+. We have determined the number of $\mathrm{Cs}^{+}$emitted by fission fragments from the CsI target. The secondary ion yield of $(M-H)^{-}$due to the impact of primary cs ions has been measured as a funciton of grid transparencies with the grids set between the CsI target and the phenylalanine target. This method is sensitive and we have found a value of $2.0 \pm 0.2$ ions emitted per fission fragment. This result is in agreement with the value found at 0rsay $/ 4 /$ and also by the Darmstadt group $/ 5,6 /$.

In the present experiment the positive primary ions are accelerated in the space between the sample and the extraction grid. Therefore the angle of incidence $B^{\prime}$ varies according to the relation:

$$
B^{\prime}=\operatorname{Arcos}\left[\left(U_{1} / U_{1}-U_{2}\right)^{1 / 2} \cdot \cos B\right]
$$

$u_{1}$ is the acceleration potential of the primary ions

$u_{2}$ is the acceleration potential of the secondary ions

$B^{2}$ is the tilt angle between the sample surface and the direction of primary beam.

The variation of $B^{\prime}$ is relatively small under our experimental condition. It has been verified that at a constant energy of impact (by varying $U_{2}$ and $\mathrm{U}_{z}$, the influence of the $B^{\prime}$ variation on the secandary yield is.negligible.

\section{RESULTS AND DISCUSSTON}

Figure 4 shows the effert of primary ion velocity on the (M-H) yield of phenylalanine due to incident coronene molecular and dimer ions (Fig. $4 a$ ) and due to incident cesium and cesium iadide cluster ions (Fig. 4b). The $x$ axis scale is given in keV per mass unit $\left(=k v^{2}\right.$ ) and therefore comparison of secondary ion yields can be made easily at the same velocity for various projectiles. The bombarding energies ranged from 7.66 keV to 28 keV. For all curves shown, the Iines drawn through the data points are to aid the eyes. Error bars for the experimental points are less than $10 \%$ in al1 cases. For the experiment using coronene as the primary ion source, primary ions of mass $73\left[S i\left(\mathrm{CH}_{3}\right)_{3}\right]$ and mass $147\left[5 i\left(\mathrm{CH}_{3}\right)_{3} \mathrm{QSi}\left(\mathrm{CH}_{3}\right)_{2}^{+]}\right.$were also observed for their desorption efficiency. The general trend is that the yields are much greater for the higher mass projectiles. For example there is at low velocity a yield 

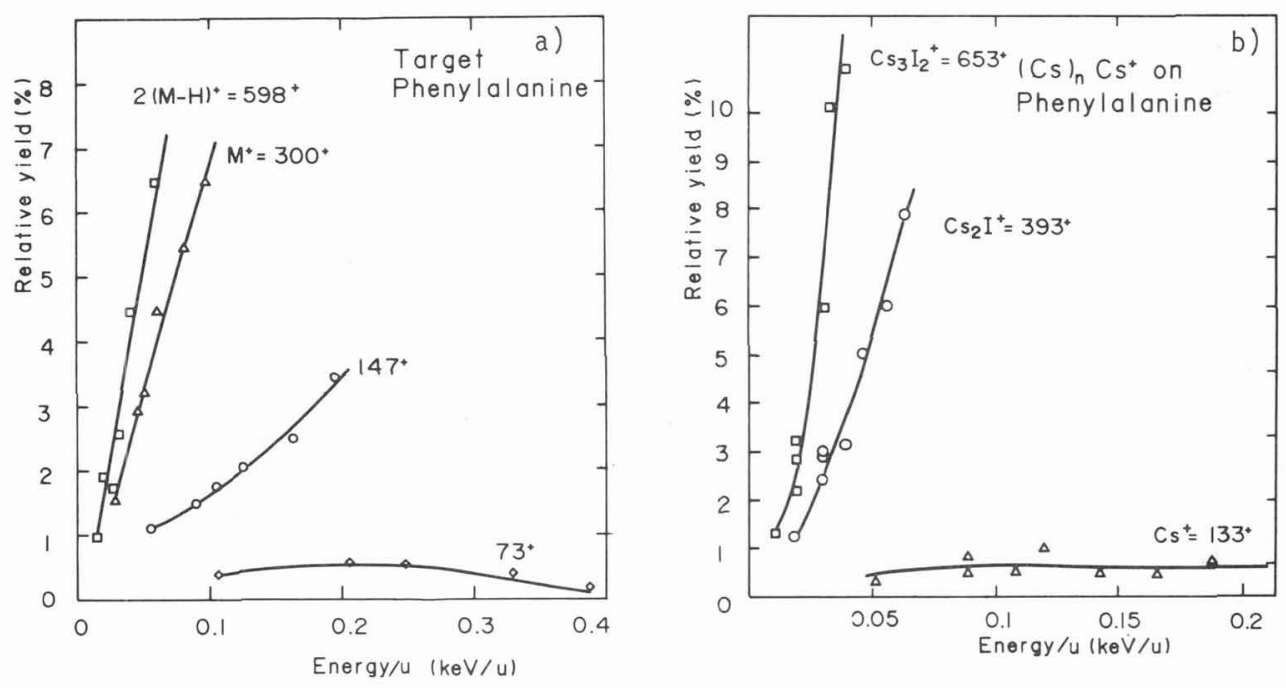

Figure 4

a) Secondary ion yield of the molecular ion $(M-H)^{-}$of phenylalanine as a function of the incident mass unit $\left(=k v^{2}\right)$ of the projectiles (coronene ions and dimers). The secondary ion, yields can be compared easily at the same velocity.

b) same as above. The projectiles are Cs ions and CsI cluster ians.

enhancement by a fattor of around 20 between $\mathrm{Cs}^{+}$and $\mathrm{Cs}_{2} \mathrm{I}^{+}$as projectiles. For cluster ions or molecular ions the rate of increase with the projectile velocity is also very important. The observed yields for ather secondary ions and the trends are the same.

\section{CONCLUSION}

The use of polyatomic ions as projectiles to induce secondary ion emission from organic solids is found to be very interesting. It is shown that single ion counting technique and coincidence methods are particularly useful for these experiments. The results presented here show that increased secondary ion yields can be achieved for the same amount of energy deposited by simply using a polyatomic, rather than a monoatomic, primary ion. It is not yet clear whether the increased yields of phenylalanine seen with the cesium iodide species and the coronene ions are due to increased mass or an increase in the number of particles in the projectile. In addition, the existence of coherent effects in the desorption process remains to be determined as the correct experimental observable remains to be identified, e.g- Y/l $\quad$ of constituents in cluster), $Y /$ (amu of projectile), $Y / \Sigma$ (dE/dx) $n$ etc. Further data analysis is in progress in order to understand the role af cluster velocity, mass, and constituent number in the yields of secondary ions.

\section{References}

$11 /$ See for example : J.P.Thomas, P.E.Filpus-Luyckx, M.Fal lavier and E.A.Schweikert, Phsy. Rev. Lett. 55 (1985) 103 ; M.Salehpour, 
D.L.Fishel, J.E.Hunt, Int. J. Mass Spec, and Ion Proc - 84 (1988) R7; S.Johar and D.A.Thompson, Surf. Sci. 90 (1979) 319 ; W. Reuther, Ana1. Chem. 59 (1997) 2061 .

$12 /$ M.G.Blain, E.A.Schweikert and E.F.Da Silveira, to be published in these praceedings.

/3/ S. Della-Negra and Y.Le Beyec, Proceedings of the $s I M S$ VI conference, Versailles, John Wiley and Sons (1988) 247.

$14 /$ S. Della-Negra, Y.Le Beyec, K.G.Standing, unpublished results.

15/ 0.Becker, K.Wien and W. Guthier, Rad. Effects 99 (1906) 217.

/6/ R.Moshammer and R.Matthaus, contribution this conference. 